\title{
Organ donation and utilization in the USA
}

\author{
Akinlolu O. Ojo ${ }^{a, *}$, Dennis Heinrichs ${ }^{b}$, Jean C. \\ Emond $^{c}$, Joshua J. McGowan', Mary K. \\ Guidinger $^{d}$, Francis L. Delmonico ${ }^{e}$ and Robert A. \\ Metzger \\ a Scientific Registry of Transplant Recipients/University of \\ Michigan, Ann Arbor, MI; \\ b LifeLink Foundation, Tampa, FL; \\ c Columbia Presbyterian Medical Center, New York, NY; \\ ${ }^{d}$ Scientific Registry of Transplant Recipients/University \\ Renal Research and Education Association, Ann Arbor, \\ $\mathrm{Ml}$; \\ 'Massachusetts General Hospital, Boston, MA; \\ f TransLife-Florida Hospital Medical Center, Orlando, FL \\ *Corresponding author: Akinlolu Ojo, aojo@umich.edu
}

The processes leading to donor identification, consent, organ procurement, and allocation continue to dominate debates and efforts in the field of transplantation. A considerable shortage of donors remains while the number of patients needing organ transplantation increases.

This article reviews the main trends in organ donation practices and procurement patterns from both deceased and living sources in the USA. Although there have been increases in living donation in recent years, 2002 witnessed a much more modest growth of $1 \%$. Absolute declines in living liver and lung donation were also noted in 2002.

In 2002, the number of deceased donors increased by only $1.6 \%$ (101 donors). Increased donation from deceased donors provides more organs for transplantation than a comparable increase in living donation, because on average $\mathbf{3 . 6}$ organs are recovered from each deceased donor. The total number of organs recovered from deceased donors increased by $2.1 \%$ (462 organs). Poor organ quality continued to be the major reason

Notes on Sources: The articles in this report are based on the reference tables in the 2003 OPTN/SRTR Annual Report, which are not included in this publication. Many relevant data appear in figures and tables included here; other tables from the Annual Report that serve as the basis for this article include the following: Tables 1.1, 1.2, 2.1-2.4, 2.8, 2.9, and 3.1-3.18. All of these tables are also available online at http://www.ustransplant.org.

Funding: The Scientific Registry of Transplant Recipients (SRTR) is funded by contract \#231-00-0116 from the Health Resources and Services Administration (HRSA). The views expressed herein are those of the authors and not necessarily those of the US Government. This is a US Government-sponsored work. There are no restrictions on its use. given for nonrecovery of consented organs from deceased donors.

The kidney is the organ most likely to be discarded after recovery. Over the past decade the discard rate of recovered kidneys has increased from $6 \%$ to $11 \%$. Many of these are expanded criteria donor kidneys.

Key words: Deceased donors, donation rates, living donors, OPOs, organ donation, organ procurement, SRTR

\section{Introduction}

Organ donation is critical and central to successful replacement of end-stage organ failure with viable allogeneic grafts. The processes leading to donor identification, solicitation and execution of consent, and organ procurement and allocation continue to dominate debates and efforts in the field of transplantation for four major reasons. First, there remains a huge shortage of donors, while the number of patients needing organ transplantation continues to increase unabatedly. Second, disparity exists between potential supply and realization of donors. Third, allocation policies remain contentious. Finally, American society is far from consensus as to the right mix of motivations to appropriately encourage more organ donation. This section reviews the main trends in organ donation practices and procurement patterns from both deceased and living sources in the USA.

Unless otherwise noted, the statistics in this article come from reference tables in the 2003 OPTN/SRTR Annual Report. Two companion articles in this report, 'Transplant data: sources, collection, and caveats' and 'Analytical approaches for transplant research', explain the methods of data collection, organization, and analysis that serve as the basis for this article $(1,2)$. Additional detail on the methods of analysis may be found in the reference tables themselves or in the Technical Notes of the OPTN/SRTR Annual Report, both available online at http://www.ustransplant.org.

\section{Overview of the US Organ Procurement System for Cadaveric Organs}

Organ donation is a dynamic process that, in one sense, may be considered complex and difficult because of the 


\section{Akinlolu O. Ojo et al.}

many institutions and people involved in every case. In another sense, it may be considered the simple caring and altruistic act of giving of one's self as either a deceased or living donor in order to help those in critical need. At the very center of our nation's highly successful provision of transplant patient care is the organ procurement organization (OPO). Currently, there are 59 OPOs providing services to the many institutional and individual constituents within their specifically delineated donation service areas (DSAs). Of these 59 OPOs, 50 are classified as independent, freestanding organizations. The remaining nine are classified as hospital-based organizations. OPOs operate under contract with the Federal government, are designated by the Secretary of Health and Human Services, are granted Medicare provider status for reimbursement, file annual cost reports, participate in the nation's Organ Procurement and Transplant Network (OPTN), and are required to adhere to a number of structural, procedural, and evolving performance standards and regulations articulated in the Federal Register (Performance Standards $\S 486.310)$.

OPOs spend a considerable amount of time, energy, and money establishing a positive donation environment in the donor hospitals within their DSAs. Specifically, OPO staff members educate hospital medical, nursing, and administrative personnel regarding potential donor identification, the donor and family consent process, and donor maintenance care prior to actual organ recovery. They work to develop strong, trusting, and collaborative relationships with the hospital's trauma, critical care, neurosurgical, and neurological specialists, because these individuals play a critical role in the success of the overall donation process. Additionally, OPOs also strive to establish collegial, supportive relationships with the medical examiner or coroner within whose jurisdiction they are located. These relationships are critical in the effort to maximize donation while meeting the needs and requirements of these important officials.

Historically, OPOs have focused a considerable amount of energy and work on developing a smoothly running donor identification and referral system at the local hospital level. It was felt that by casting a wider net, OPO staff would have an increased opportunity to meet with a greater number of potential donor families and thereby be able to expand the number and rate of actual donations. Fortunately, this process of identifying all suitable potential donors was greatly aided by Federal and state legislative efforts focused on routine referral hospital strategies. OPOs continue to refine the referral process at all of their donor hospitals with an enhanced focus on those hospitals having the greatest donor potential.

\section{Consent to Organ Donation}

With the donor identification and referral systems now largely in place, the critical area of donor consent has come to the forefront. In general, OPOs have tried to shift the burden of requesting from hospital staff to OPO staff. OPOs have focused on expanded training for those who obtain consent and, in some cases, use only staff members who have historically demonstrated their abilities at obtaining consent.

It is important to note that ongoing public and professional educational efforts continue to grow at a steady pace. The current Federal administration and its supporting agencies and divisions have been particularly focused on this important issue. A number of new initiatives are well under way, and additional ones are under consideration. One of the most exciting initiatives seeks to bring together the leadership of key participants in the donation process (i.e. hospital administration, medical examiners, OPOs, accrediting bodies, medical and surgical practitioners, critically related associations, and others) and develop collaborations focused on real process improvements. The work of the Association of Organ Procurement Organizations (AOPO), the United Network for Organ Sharing (UNOS), the Coalition on Donation, and the Southeastern Organ Procurement Foundation (SEOPF), among others, in public outreach and donation-related education is also noteworthy.

In many states, living individuals may indicate their intent to donate in the event of their death. Adding one's name to a registry during life may leave less ambiguity about a decedent's organ donation preferences. There continues to be ongoing discussion concerning the role of donor registries in the consent process, as well as consideration of ways to link such registries to improve their usefulness. New legislative acts, referred to as 'first-person consent laws', have been promulgated to make it possible for donation to take place using the donor's valid donor card, entry onto a donor registry, or driver's license indication without seeking the consent of the legal next-of-kin. This reaffirmation of the donor's intent represents a paradigm shift from the current practice of relying upon donor next-of-kin for consent.

For the past three decades, consent for recovery of organs from deceased donors has been obtained primarily from the donor family or legal surrogate. This occurred in spite of the Uniform Anatomical Gift Act of 1968 (UAGA), which established the precedence of donor authorization, that is, of the donor's wishes being legally binding. OPO personnel, however, have been reluctant to seek donor authorization for several reasons: the numbers with authorization were small, locating and validating authorization was difficult, and it was feared that upsetting the family by pursuing recovery against their wishes might result in adverse publicity or legal action. Supporting the donor family through the consent process therefore became a primary goal for many. It was noted, however, that the donor family consent rate approached 95-100\% when the donor's wish to donate was known by the family before death (3). More recently, several OPOs have established policies to seek 
and honor the donor's authorization while supporting the donor family through the process of accepting the decision of their loved one. Policies have also been established regarding ways to proceed with the recovery of organs when the family disagrees with the authorization (B. Brosnick, personal communication.).

These efforts have resulted in several states passing legislation that reaffirms the UAGA laws, establishing more efficient and proactive state registries with 24-h data access and providing the legal security desired by the OPOs to honor the donor's wishes. This precedence of donor authorization and the pursuit of donor rights legislation in all 50 states were strongly endorsed by the participants of a recent Consensus Conference on the Consent Process conducted by the UNOS and subsequently by other organizations including the Advisory Committee on Transplantation (ACOT) to the Secretary of the Department of Health and Human Services, AOPO, the Council of the American Society of Transplant Surgeons (ASTS), and the OPTN/UNOS Board of Directors (3). The challenge remains how best to motivate the public to embrace this responsibility of donation. The goals must be to expand the pool of potential donors from a steady, but insufficient consent rate of $50 \%$ to a positive environment in which individuals routinely authorize donation of their own organs and provide donated organs in all medically suitable situations.

In 2002, the number of deceased donors increased by only $1.6 \%$ (101 donors). As indicated in this report last year, a modest increase in donation from deceased donors will provide considerably more organs for transplantation than a substantially greater increase in living donors, because the average number of organs recovered from deceased donors is 3.6 (4).

The total number of organs recovered from deceased donors has increased by $2.1 \%$ (462 organs) since 2001. This includes increases of 195 kidneys (2\%), 56 pancreata $(3 \%), 184$ livers (4\%), and 84 lungs (5\%). The number of hearts decreased by 54 (2\%), continuing the steady decline since a peak of 2525 in 1994 (Figure 1).

\section{Nonrecovery of consented organs}

Consent was obtained for 41273 organs in 2002, but only 22460 were recovered. The usefulness of these figures is limited, however, because consent is usually obtained by OPO coordinators for the recovery of all organs. The consent process often occurs before the evaluation of individual organs is complete and offers are made to potential recipients, therefore an indeterminate number of cases result in consent for donation of organs that will ultimately be deemed not suitable for transplantation. Thus, a large proportion of pancreata (61\%), intestines (97\%), hearts (50\%), and lungs (83\%) from donors whose family gave consent were not recovered compared with smaller numbers of nonrecovered kidneys (7\%) and livers (11\%) (Figure 2).

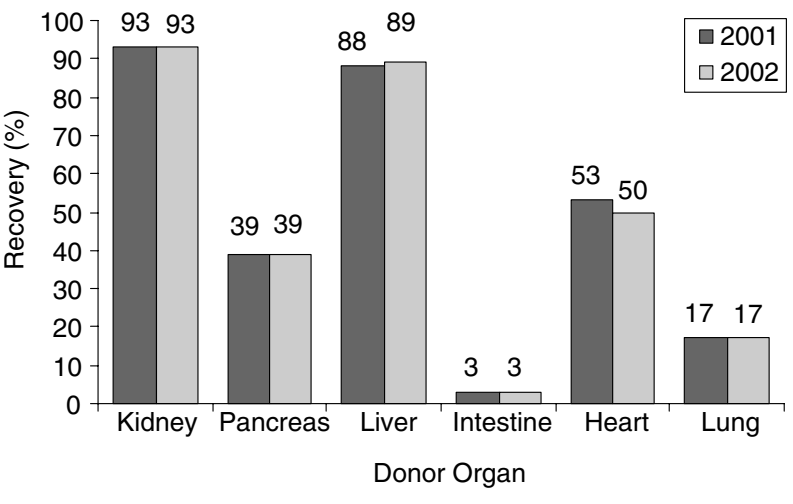

Source: 2003 OPTN/SRTR Annual Report,

Tables 3.1, 3.3, 3.4, 3.6, 3.7, 3.9, 3.10, 3.12, 3.13, 3.15, 3.16, 3.18.

Figure 1: Organ recovery rates from deceased donors, 2001 and 2002.

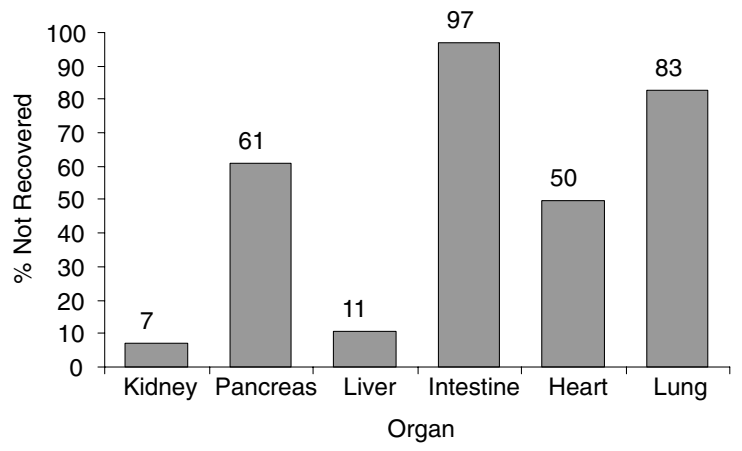

Source: 2003 OPTN/SRTR Annual Report

Tables 3.1, 3.3, 3.4, 3.6. 3.7, 3.9, 3.10, 3.12, 3.13, 3.15, 3.16, 3.18.

Figure 2: Nonrecovery of consented organs, 2002.

Poor organ quality-a combination of poor organ function/infection and the organ unsatisfactory category (organ damage or anatomic abnormalities)—continued to be the major reason coded for nonrecovery of consented organs. This reason was recorded for $61 \%$ of nonrecovered kidneys, $48 \%$ of nonrecovered pancreata, $60 \%$ of nonrecovered livers, $29 \%$ of nonrecovered intestines, $64 \%$ of nonrecovered hearts, and $76 \%$ of nonrecovered lungs. A greater percentage of intestines, however, were not recovered due to the lack of an available recipient (35\%) than for organ quality. Although poor organ quality appears to be an increasing cause of nonrecovery over the past 10 years, this may be a reflection of more specific data entry, given that the category 'other' has decreased to a similar degree.

The decision to abandon the recovery of consented organs, as determined by OPO and transplant personnel, can be subjective and variable. Additional effort needs to be directed toward improving the ability of all organizations to accurately assess the suitability of individual organs for 
transplantation and to develop national standards for this decision-making process.

\section{Consent for organ donation by type, organ, and year}

As discussed above, successful identification and appropriate medical management of an eligible deceased donor may not result in organ donation because the next-of-kin or the individual acting as guardian may not grant consent. In a recent study conducted by Sheehy et al. under the auspices of the AOPO, medical record reviews in 36 OPOs (covering approximately one-half of the entire US population) showed that an average of $54 \%$ of families approached gave consent for deceased organ donation (5). In this study, the mean consent rate (proportion of families asked who gave consent) ranged from 42-69\%. Apart from the geographic disparity in consent rates, marked variation exists in consent rates by ethnicity, with minorities exhibiting consent rates one-half that of nonHispanic whites (6). There are multiple reasons why consent rates vary. These include demographic differences across DSAs, religious perceptions, poor communication between grieving families and health care providers, perceived inequities in the allocation system, and lack of knowledge of the wish of the deceased (6). In addition, variability in the timing of referrals from hospitals may have an impact on the opportunity for OPO requestors to meet with families to discuss donation, and the level of interpersonal skill and sensitivity of requestors may not be uniform across all OPOs (7). Ethnicity appears to be a strong predictor of willingness to consent to donation (5). African-Americans consistently have lower consent rates in multicenter studies, although higher consent rates have been cited in single-center studies (8). It is unknown whether presumed consent (opt-out) provisions would significantly affect consent rates in the USA (8-10).

\section{Organs from Deceased Donors}

\section{Donation after cardiac death}

The recovery of organs from donors after cardiac death (DCD) - the norm in the early years of transplantationwas all but abandoned in the 1970s and 1980s with the acceptance of brain death criteria. When death is determined by the irreversible cessation of circulatory and respiratory function, the donor has had an obligate period of hypotension followed by cardiac arrest prior to organ recovery. Detrimental effects on organ function from the requisite warm ischemia time and associated higher rates of delayed graft function prompted most centers to rely solely on brain-dead, heartbeating donors. As the gap between supply and demand for solid organs continues to widen, however, more centers are reassessing the use of organs from DCD donors. Two important papers were recently published examining long-term function of kidneys from DCD donors $(11,12)$. Webb et al. in a single-center study from Zurich, found no difference in death-censored graft function at 5 and 10 years in kidneys from DCD donors compared with brain-dead donors, in spite of a much higher incidence of delayed graft function in the former (11). At 10 years, the death-censored rate of graft survival was $78.7 \%$ for kidneys from DCD donors and $76.7 \%$ for kidneys from brain-dead donors. Forty-six per cent of their donors were uncontrolled, following unsuccessful cardiac resuscitation (Maastricht category II). Rudich et al. in an analysis of adult deceased donor transplants registered in the United States Renal Data System (USRDS) between January 1993 and June 2000, found the 6-year death-censored graft survival comparable between DCD donors (73.2\%) and brain-dead donors $(72.5 \%)$, despite nearly twice the incidence of delayed graft function in the DCD donors (12). These studies provide convincing evidence that kidneys recovered from DCD donors, after the attending physicians and family determine it appropriate to withdraw supportive therapy, provide very acceptable kidneys for transplantation.

Nonetheless, the use of DCD donor kidneys remains low. In 2002, organs were recovered from 191 DCD donors, accounting for $3 \%$ of total deceased donors and a $13 \%$ increase from 2001. These donors produced 185 kidneys, 22 pancreata, and 103 livers.

The effort required by OPOs to initiate recovery programs for DCD donors is substantial, requiring considerable investment in time and resources, constructing protocols to be approved by hospital ethics and patient care committees, and training intensive care unit, emergency department, and operating room personnel. The potential for a $20-25 \%$ increase in the overall number of deceased donors, however, would be well worth the effort (13).

\section{Expanded criteria donors}

The allocation system for the expedited placement of defined ECD kidneys was discussed in last year's report and was activated in November 2002 (14). Data will be available for the 2004 OPTN/SRTR Annual Report regarding results from the first year of this attempt to improve the use of organs from these donors.

\section{Number of organs recovered per donor by year}

Table 1: Mean number of organs recovered per deceased donor, 2000-02

\begin{tabular}{ll}
\hline $\begin{array}{l}\text { Age group } \\
\text { (years) }\end{array}$ & $\begin{array}{l}\text { Recovered organs/ } \\
\text { deceased donor }\end{array}$ \\
\hline$<1$ & 2.8 \\
$1-5$ & 3.3 \\
$6-10$ & 3.7 \\
$11-17$ & 4.5 \\
$18-34$ & 4.3 \\
$35-49$ & 3.6 \\
$50-64$ & 3.0 \\
$65+$ & 2.4 \\
\hline
\end{tabular}

Source: OPTN/SRTR data as of August 1, 2003. 


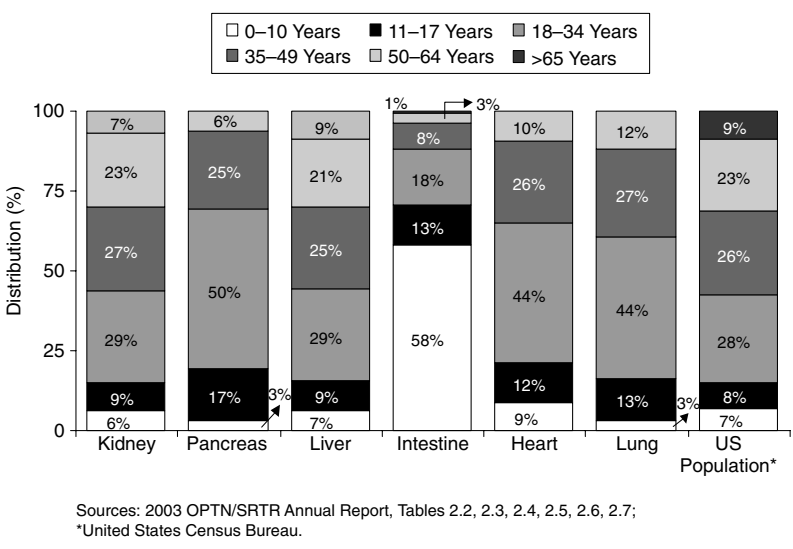

Figure 3: Distribution of cadaveric organ donations by age, 2002.

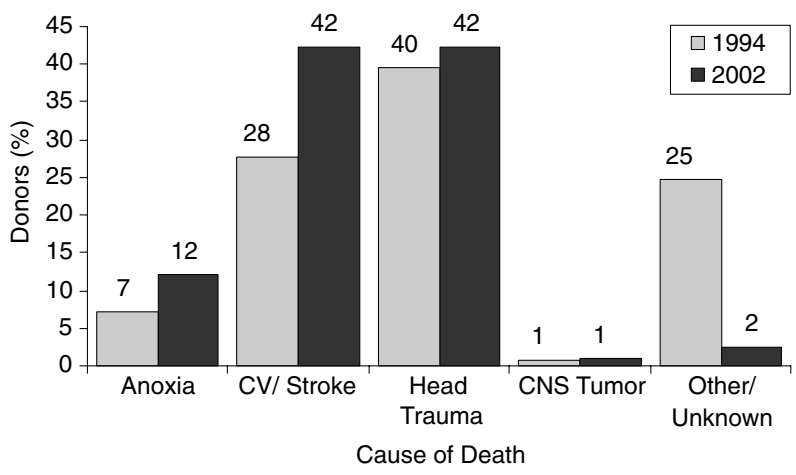

Note: 5362 deceased donors in 1994; 6081 in 2002. Source: 2003 OPTN/SRTR Annual Report, Table 2.1.

Figure 4: Percentage cause of death for organ donors, 1994 vs. 2002.

Transplant suitability of donated organs varied by the age of the deceased and cause of death. Distribution of donor age and cause of death are shown in Figures 3 and 4, respectively. Due to these variations in suitability, the number of organs recovered from each donor differed according to the characteristics of the deceased. The mean number of organs for all deceased donors from 2000 to 2002 was 3.6 organs per donor. Table 1 shows the mean number of organs recovered by age group, from January 1, 2000 to December 31, 2002.

The number of organs recovered is also directly influenced by conditional consent, whereby families of the deceased grant consent for donation but specify that certain organs should not be removed. This behavior is prevalent and contributes significantly to differences in the availability of organs by organ types. Table 2 shows details on organs for which consent was not obtained, with both prevalence of and reasons shown by organ type. The proportion of refusals because of emotional reasons is fairly constant; the sole exception is for livers, which have a statistically significantly higher proportion of refusals because of emo- tional reasons than the overall average. The data suggest that tailored educational efforts should be directed at the public to address perceptions underlying this refusal behavior. It seems such educational effort would need to be organ specific, because general messages conveying the need for more organ donors apparently do not sufficiently address beliefs underlying organ-specific denial of consent.

\section{Organ disposition among donors by year and by organ}

Background. Over the past decade, there has been a progressive increase in the number of deceased donors available for transplantation, from 4861 in 1993 to 6182 in 2002. Unfortunately, this increase has been accompanied by an even greater growth in demand, necessitating further improvement in our use of this resource. Below we seek to identify the magnitude of the opportunity for increasing use of donated organs.

There is currently a loss of potential organs at each step between the time a family agrees to permit recovery of organs from a deceased donor and the time the individual organs are transplanted. This attrition between donation and transplantation exerts an enormous impact on the candidate population. Unlike overall consent rates and donation rates, which can only be modified by large-scale societal interventions, an improvement in the rate of use of donated organs might be achieved by changes in practice within the transplant community. Some causes of nonutilization are intrinsic to the health status of the donor, while others relate to logistic failures at the recovery agency, the transplant centers, or both. Finally, there is an ethical balance between the perceived need for the donated organ and the willingness of the transplant team to extend the medical and technical criteria for use of an organ from a given donor. There are many more issues that affect the utilization of available organs, which are, in many respects, related to the willingness of transplant centers to consider organs from expanded criteria donors (ECDs). The need to more aggressively utilize available organs for the candidate population as a whole competes with the expectation of each individual candidate for an optimal organ. The use of ECD organs requires structured analysis of the overall morbidity faced by the population on the waiting list, as well as an assessment of the impact of an organ with a particular risk factor for poor function or the transmission of disease on the outcome of an individual transplant. Such analyses have recently been performed by the SRTR pertaining to the use of ECD organs in kidney transplantation $(14,15)$. Public focus on the decision to confer risk in graft selection has necessitated greater attention on informed consent for the individual recipient in the face of such risk factors, like the potential transmission of an infectious disease from donor to recipient.

It is likely that some of the nonrecovery and nonuse of donor organs may be attenuated by modifications of donor 
Akinlolu O. Ojo et al.

Table 2: Individual organs for which consent was not obtained (totals, percentage, and reasons cited), 1999-2001

\begin{tabular}{|c|c|c|c|c|c|c|c|}
\hline \multirow[b]{2}{*}{ Organ } & \multirow[b]{2}{*}{$n$} & \multirow{2}{*}{$\begin{array}{l}\% \text { Without } \\
\text { consent* } \\
(95 \% \mathrm{Cl})\end{array}$} & \multicolumn{5}{|c|}{ Reasons consent not obtained, n (\%) } \\
\hline & & & Religious & Emotional & Cultural & $\begin{array}{l}\text { Family } \\
\text { conflict }\end{array}$ & Other/unknown \\
\hline Heart & 700 & $\begin{array}{l}4.1 \\
(3.8-4.5)\end{array}$ & $7(1)$ & $502(71.7)$ & $14(2)$ & $59(8.4)$ & $118(16.9)$ \\
\hline Intestine & 1971 & $\begin{array}{l}11.7 \\
(11.1-12.3)\end{array}$ & $6(0.3)$ & $1467(74.4)$ & $17(0.9)$ & $128(6.5)$ & $353(17.9)$ \\
\hline Kidney & 106 & $\begin{array}{l}0.6 \\
(0.5-0.7)\end{array}$ & $1(0.9)$ & $75(70.8)$ & $0(0)$ & $7(6.6)$ & $23(21.7)$ \\
\hline Liver & 225 & $\begin{array}{l}1.3 \\
(1.2-1.5)\end{array}$ & $1(0.4)$ & $180(80.0)$ & $4(1.8)$ & $9(4)$ & $31(13.8)$ \\
\hline Lung & 1015 & $\begin{array}{l}6 \\
(5.6-6.4)\end{array}$ & $5(0.5)$ & 734 (72.3) & $10(1)$ & $87(8.6)$ & $179(17.6)$ \\
\hline Pancreas & 826 & $\begin{array}{l}4.9 \\
(4.6-5.2)\end{array}$ & $5(0.6)$ & $604(73.1)$ & $10(1.2)$ & $63(7.6)$ & $144(17.4)$ \\
\hline
\end{tabular}

Source: SRTR analysis for the ACOT Heart and Lung Allocation Committee, May 30, 2002. Differences in rate are statistically significant. Based on number of donors who had donated at least one organ with at least one other organ not donated because consent was not obtained $(n=2435)$. *Based on total number of donors for the period $(n=16903)$.

Table 3: Disposition of consented organs, 2002

\begin{tabular}{|c|c|c|c|c|c|}
\hline Organ & $\begin{array}{l}\text { Total number } \\
\text { of organs } \\
\text { consented }^{1}\end{array}$ & $\begin{array}{l}\text { Percentage of } \\
\text { nonrecovered } \\
\text { organs }^{2}\end{array}$ & $\begin{array}{l}\text { Percentage of } \\
\text { organs } \\
\text { transplanted }{ }^{3}\end{array}$ & $\begin{array}{l}\text { Percentage of } \\
\text { organs } \\
\text { discarded } 4\end{array}$ & $\begin{array}{l}\text { Percentage of } \\
\text { organs used } \\
\text { for research }\end{array}$ \\
\hline Heart & 4436 & 49.9 & 49.2 & 0.2 & 0.1 \\
\hline Intestine & 4070 & 97.2 & 2.6 & $<0.1$ & $<0.1$ \\
\hline Kidney & 12040 & 7.1 & 80.4 & 10.6 & 1.8 \\
\hline Liver & 6018 & 10.8 & 82.5 & 3.1 & 3.4 \\
\hline Lung & 9938 & 82.8 & 16.3 & 0.4 & 0.2 \\
\hline Pancreas & 4771 & 60.8 & 30.4 & 7.0 & 1.5 \\
\hline
\end{tabular}

Source: 2003 OPTN/SRTR Annual Report, Tables 3.1-3.18.

${ }^{1}$ Includes both recovered and nonrecovered organs for which consent was obtained.

${ }^{2}$ Donated organ not removed for medical reasons after consent was obtained.

${ }^{3}$ Donated organ was transplanted as intended.

${ }^{4}$ Donated organ was recovered but discarded because it was not transplantable or suitable for research.

${ }^{5}$ Donated organ was recovered, found to be not suitable for transplantation but used for research instead of being discarded.

management, selection practices by the transplant centers, or adjustments in the logistics of procurement and allocation. Recognition of an opportunity to enhance the efficiency of use of consented donors for all the organs led to a consensus at an important conference in Crystal City, Maryland, in 2002. Although many topics were considered at this meeting, attention was focused on four principal areas: tissue-matching based allocation of kidneys, medical management of heart and lung donors, the splitting of livers, and donor selection issues related to previous viral or neoplastic conditions of potential organ donors (16).

2002 Disposition data. Disposition of organs, including nonrecovery of organs from consented donors, organ discard, and use of recovered organs for research, varied by the type of organ. Table 3 shows the rates of nonrecovery and discard of recovered organs for 2002. As noted above, almost half (46\%) of the 41273 organs consented for donation in 2002 were not recovered, with heart, intestine, and lung accounting for $12 \%, 21 \%$, and $44 \%$ of nonrecovered organs, respectively. After poor organ function, infection with hepatitis virus and/or HIV was the second most common recorded cause for nonrecovery. Less than $2 \%$ of all donated organs were ultimately used for research. Discard of recovered organs was highest for kidneys at $11 \%$.

\section{Nonutilization of organs from consented donors}

To identify opportunities for increasing use of available donors, we have displayed OPTN data to estimate the 'use efficiency' of consented donors, which is the basis of this analysis. If the denominator of total consented donors is used as the baseline estimate of real potential, and the actual number of organs transplanted the numerator, the gap between the two represents 'nonutilization' of donated organs. Loss occurs in two phases, nonrecovery of organs from consented donors, and nonuse of recovered organs. The standard reasons for nonrecovery, as reported to the OPTN, are cardiac arrest, organ unsatisfactory, poor 
Table 4: Nonutilization by organ, 2002 and 1993

\begin{tabular}{|c|c|c|c|c|c|}
\hline & $\begin{array}{l}\text { Potential organs } \\
\text { (deceased donors) }\end{array}$ & $\begin{array}{l}\text { Consent not } \\
\text { recovered }\end{array}$ & Percentage & $\begin{array}{l}\text { Recovered } \\
\text { not used }{ }^{2}\end{array}$ & Percentage \\
\hline \multicolumn{6}{|c|}{ Organ nonuse 2002} \\
\hline Heart & 6182 & 2215 & 35.8 & 11 & 0.2 \\
\hline Lung & 12364 & 8231 & 66.6 & 38 & 0.3 \\
\hline Liver & 6182 & 649 & 10.5 & 185 & 3.0 \\
\hline Kidney & 12364 & 858 & 6.9 & 1273 & 10.3 \\
\hline Pancreas & 6182 & 2901 & 46.9 & 329 & 5.33 \\
\hline Intestine & 6182 & 3960 & 64.1 & 4 & 0.1 \\
\hline \multicolumn{6}{|c|}{ Organ nonuse 1993} \\
\hline Heart & 4861 & 1174 & 24.2 & 32 & 0.7 \\
\hline Lung & 9722 & 5892 & 60.6 & 48 & 0.5 \\
\hline Liver & 4861 & 802 & 16.5 & 193 & 4.0 \\
\hline Kidney & 9722 & 385 & 4.0 & 566 & 5.8 \\
\hline Pancreas & 4861 & 2261 & 46.5 & 76 & 1.6 \\
\hline Intestine & 4861 & 21 & 0.4 & 4 & 0.1 \\
\hline
\end{tabular}

Source: 2003 OPTN/SRTR Annual Report, Tables 3.2-3.6, 3.8, 3.9, 3.11, 3.12, 3.14, 3.15, 3.17, 3.18.

${ }^{1}$ Consent not recovered: represents organ donors from whom organs were not removed after consent was obtained because of medical contraindication that was not evident prior to consent or lack of organ viability detected by testing or intraoperatively.

${ }^{2}$ Recovered not used: organs that were recovered and subsequently found to be unsuitable for transplantation.

organ function/infection, donor medical/social history, biopsy findings, positive hepatitis/HIV/HTLV-1, no recipient found, unknown, and other. The OPTN reporting categories for reasons of nonuse are similar, but include extended ischemia time and positive hepatitis/CMV/HIV and do not include cardiac arrest or positive hepatitis/HIV/HTLV-1.

Nonrecovery of consented organs accounts for the majority of nonutilization, with 'poor organ function/infection' as the leading category for all organs (ranging from $27 \%$ for intestines to $71 \%$ for lungs). It should be noted that the data presented count two lungs for each donor, thus overestimating potential, because many lung transplants require both lungs for a single recipient. Categories such as 'poor organ function' are extremely subjective and are likely to vary substantially between regions depending on practice patterns among the transplant centers. In contrast to the other organs, 'no recipient found' was the most common reason for nonrecovery of intestines. This reflects the status of intestine replacement as an emerging therapy for intestine failure, rather than the standard of care.

Although nonrecovery of consented donors was by far the largest contributor to nonutilization, nonuse of recovered organs occurred frequently in some organ systems; 1275 kidneys and 333 pancreata were recovered but not used in 2002. This is likely to be due to the collective retrieval systems that are present in most OPOs, in which the organs are recovered as a collective responsibility before the intended recipients are determined. In contrast, hearts (11) and lungs (39) were rarely declined at this phase in the process, because the recipient surgery usually begins at the time of retrieval from the donor. Livers were discarded more often, usually due to biopsy data that became available after the recovery was completed.
The rates of nonrecovery and nonuse by organ are presented in Table 4. There are obvious differences between the organs in terms of the ability to function following retrieval and implantation, which naturally leads to distinct patterns of organ selection by the transplanting teams. For example, heart, lung, and liver recipients need immediate function of the grafts to sustain life. While livers can be replaced emergently, this option rarely succeeds in heart and lung transplantation.

\section{Number and percentage of recovered organs discarded by year and by organ}

There is substantial variation in the utilization of organs from consenting donors among transplant types. For example, although there were 6182 consenting donors in 2002, only $2221(36 \%)$ resulted in a heart transplant while 5292 $(86 \%)$ resulted in a liver transplant (Table 4). Over the past decade, there has been a marked increase in the use of livers and a more modest increase in the use of lungs, pancreata, and intestines, while there has been a proportional decrease in the use of hearts and kidneys. The decrease in the use of hearts and kidneys may be relative because much of the increase in donation between 1993 and 2002 occurred in the older age groups, which are less likely to be selected for heart and kidney donation. For example, in the older age groups (50-64 and 65+), 859 more donors were used in 2002 than in 1993.

In addition to variation in the use of donors by organ, there is variation among OPOs reflecting different practice patterns between transplant centers and the difficulties of long-distance sharing. Unfortunately, such variations are not discernible when working with aggregate data. This is important because improvements in policy and practice need to deviate mean performance toward the results 
Akinlolu O. Ojo et al.

Table 5: Transplant rates of consented donors by organ, 2002 and 1993

\begin{tabular}{|c|c|c|c|c|c|}
\hline & $\begin{array}{l}\text { Potential organs } \\
\text { (deceased donors) }\end{array}$ & $\begin{array}{l}\text { Local } \\
\text { transplants }\end{array}$ & $\begin{array}{l}\text { Shared } \\
\text { transplants }\end{array}$ & $\begin{array}{l}\text { Total } \\
\text { transplants }\end{array}$ & $\begin{array}{l}\text { Use } \\
\text { ratio }\end{array}$ \\
\hline \multicolumn{6}{|c|}{ Organ use 2002} \\
\hline Heart & 6182 & 1410 & 773 & 2183 & 35.3 \\
\hline Lung & 12364 & 944 & 675 & 1619 & 13.1 \\
\hline Liver & 6182 & 3532 & 1431 & 4963 & 80.3 \\
\hline Kidney & 12364 & 6974 & 2707 & 9681 & 78.3 \\
\hline Pancreas & 6182 & 1023 & 427 & 1450 & 23.5 \\
\hline Intestine & 6182 & 27 & 78 & 105 & 1.7 \\
\hline \multicolumn{6}{|c|}{ Organ use 1993} \\
\hline Heart & 4861 & 1653 & 696 & 2349 & 48.3 \\
\hline Lung & 9722 & 565 & 430 & 995 & 10.2 \\
\hline Liver & 4861 & 1894 & 1493 & 3387 & 69.7 \\
\hline Kidney & 9722 & 6058 & 2233 & 8291 & 85.3 \\
\hline Pancreas & 4861 & 594 & 178 & 772 & 15.9 \\
\hline Intestine & 4861 & 15 & 19 & 34 & 0.7 \\
\hline
\end{tabular}

Source: 2003 OPTN/SRTR Annual Report, Tables 3.1, 3.4, 3.7, 3.10, 3.13, 3.16.

achieved in the best practice if we are to better serve the candidates on the waiting list. As an example, the use of livers might be increased with a move to more aggressive donor selection: overall, 4963 (80\%) of consented donors resulted in liver transplants in 2002, whereas in New York state, livers were used from $88 \%$ of donors (17). If that rate were replicated nationally, an additional 582 liver transplants would result.

Allocation of organs leads to either local use or shared use, under systems that vary by organ (Table 5). Organs may be shared outside the local OPO either within the region or nationally. Kidneys are shared under a system largely driven by tissue typing, while other organs leave the region only after they have been rejected for use by the local centers, often based on an assessment of 'donor quality'. It is unfortunate that, under this system, organs of the lowest quality need to travel the farthest, presumably incurring the greatest ischemic time. The fact that so many organs are used successfully despite being turned down locally suggests that selection criteria remain highly subjective and far from perfect. This effect is not inconsiderable, because $35 \%$ of hearts and $27 \%$ of livers are used outside local OPOs (a small number of OPOs have no local extrarenal transplant centers, but these tend to serve small populations).

Failure to transplant organs recovered for that purpose (organ discard) occurs at a much lower frequency compared with nonrecovery, as noted above (Figure 5). The kidney is the organ most likely to be discarded after recovery has occurred. In 2002, $11 \%$ of recovered kidneys were discarded. This represents an $87 \%$ increase in the discard rate for recovered kidneys since 1993, when the discard rate was $6 \%$. Biopsy findings after recovery remains the dominant cited reason, representing $42 \%$ of kidneys discarded in 2002. The increase in discard rate from 1993 to 2002 was $191 \%$ for pancreas, but the discard rate fell by $32 \%$ for liver and $62 \%$ for heart. Reasons for the decline in discard rates for heart and liver have not been systemat-

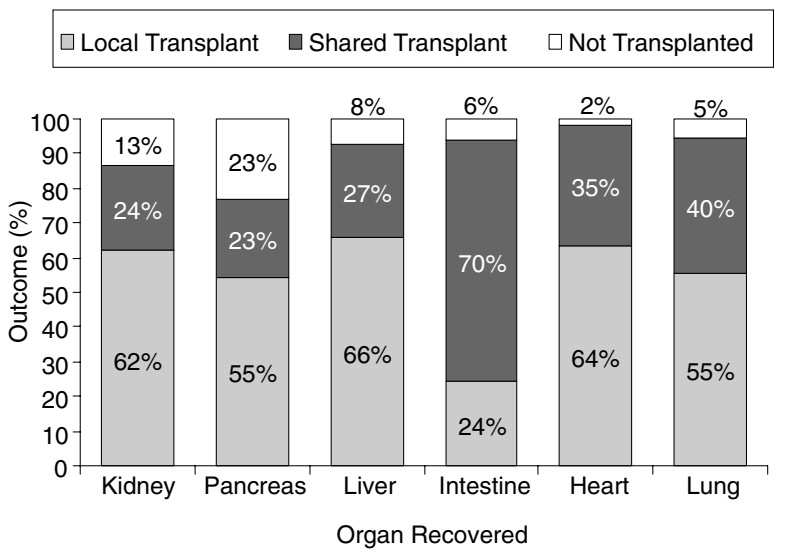

Source: 2003 OPTN/SRTR Annual Report, Tables 3.1, 3.4, 3.7, 3.10, 3.13, 3.16.

Figure 5: Cadaveric organ recovery outcomes, 2002.

ically evaluated. Unlike kidneys, once an extrarenal organ is procured, the ability to successfully place it is very limited if the original procuring team elects not to go ahead with the transplant. In addition, the risk of unreimbursed procurement expenses may encourage nonrecovery when extrarenal organ function is questionable, thereby paradoxically decreasing the rate of discard by increasing the rate of nonrecovery.

\section{Living Donors}

\section{Characteristics of living donors}

As in 2001, the number of living organ donors (6618) exceeded the number of deceased donors (6182), but the dramatic increase in live donors seen during the past decade may be slowing (Figure 6). This was especially apparent in the significant declines in 2002 in living liver and living lung donors (31\% and $36 \%$ decrease, respectively), but also in the modest $4 \%$ increase in living kidney donors compared 


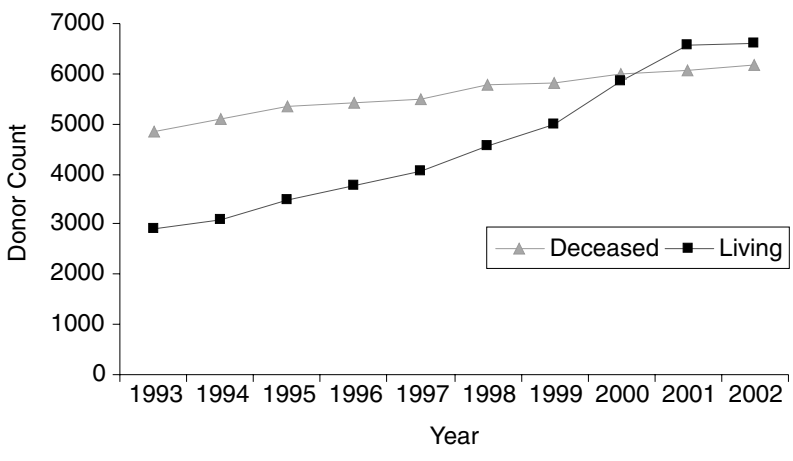

Source: 2003 OPTN/SRTR Annual Report, Table 1.1

Figure 6: Deceased and living donors, 1993-2002.

with the $11 \%$ increase the previous year. This may reflect a reappraisal of policies in the wake of a well-publicized donor death (18).

Emancipated minors (donors under 18 years of age) are rarely living organ donors. Between 1993 and 2002, there were 35 emancipated minors who underwent living kidney donation procedures. These donors accounted for less than $0.1 \%$ of all living donors, and there does not appear to be a trend (the average number of donors is four per year). As stated earlier, the total number of living donors exceeded the number of deceased donors for the first time in 2001 (6560 vs. 6081). This trend continued in 2002, during which there were 6618 living donors compared with 6182 deceased donors. It is notable that the number of living donors changed minimally between 2001 and 2002 (6560 vs. 6618). This trend is in marked contrast with the preceding 5 years, during which the number of living donors increased annually by 500-1000 donors. If the current trend persists, it may signal a stabilization of the number of living donors.

Racial composition of living donors has not changed significantly. In 1993, whites, African-Americans, Asians, and other races accounted for $83 \%, 14 \%, 2 \%$, and $1 \%$ of living donors, respectively, with the corresponding numbers for 2002 being $83 \%, 13 \%, 3 \%$, and 2\%, respectively. Demographically, the age of living donors appears to be shifting toward older donors (Figure 7). In 1993, 43\% of living donors were 18-34 years old, and this proportion declined gradually to $33 \%$ in 2002 . In contrast, the $50-64$ years age group accounted for $15 \%$ of living donors in 1993 and $18 \%$ in 2002. There was no noticeable change in the distribution of donors from the other age groups during this follow-up period, although the absolute number of living donors aged 65 years and older increased from 28 in 1993 to 61 in 2002.

\section{Living donor relation to recipient by year and by organ}

Interesting trends, with potentially important implications, are noted in the relationship of living donors and their re-

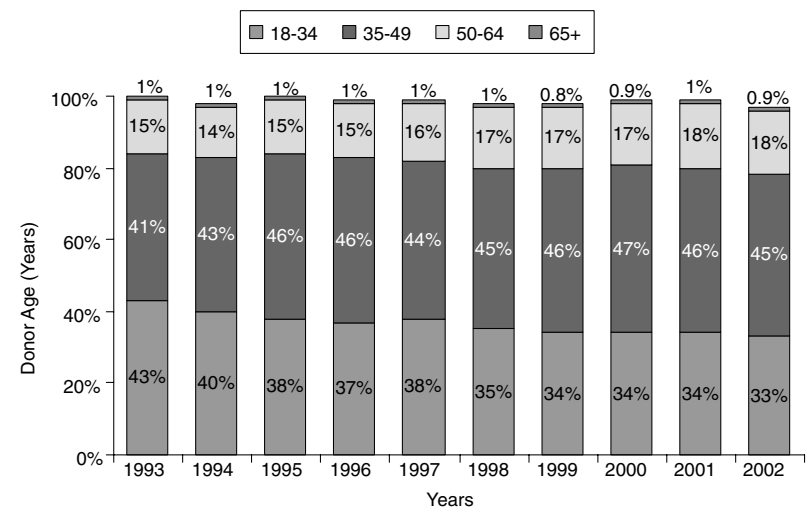

Source: 2003 OPTN/SRTR Annual Report, Table 2.8

Figure 7: Living donor age, 1993-2002.

cipients. Table 6 shows trends in the distribution of living donors according to the relationship with the recipients. Half-siblings account for just $1 \%$ of living donors, but full siblings, who previously comprised nearly one-half of all living donors (45\% in 1993), represented only $28 \%$ of living donors in 2002. The fraction of offspring, spousal donors, and nonspousal unrelated donors continued to increase over the same time period.

\section{Living donors by organ}

Kidney donors continue to make up the overwhelming proportion of living donors (94\% in 2002). Lung lobe donors declined from 56 in 1999 to 34, 39, and 25 in 2000, 2001, and 2002, respectively. A marked decrease was observed in the number of living liver segment donors in 2002 (Figure 8). The decline between 2001 and 2002 occurred in all age groups and donor-recipient relationships of liver donors and may be related to the negative publicity following the death of a living donor and the moratorium imposed on some living donor liver transplantation programs (19-21).

\section{Summary}

The existing 59 OPOs function at the center of the deceased donor organ donation process in the USA. The OPOs continue to play a critical role in expanding the science of donation and in the development of policies and methods to enhance the realization of deceased donor potential in the USA. Rates of nonrecovery and discard of organs from deceased donors remains high. Although there have been more living donors than deceased donors in recent years, 2002 witnessed a much more modest growth from this source. Absolute declines in living liver and lung donation were also noted in 2002. Further research is needed to identify all donors, improve consent rates, and reduce rates of nonrecovery and discard. 
Akinlolu O. Ojo et al.

Table 6: Percentage distribution (number) of living donors according to relationship to recipients, 1993-2002

\begin{tabular}{|c|c|c|c|c|c|c|c|c|c|c|}
\hline Relationship & 1993 & 1994 & 1995 & 1996 & 1997 & 1998 & 1999 & 2000 & 2001 & 2002 \\
\hline Parent & $\begin{array}{l}25.7 \% \\
(747)\end{array}$ & $\begin{array}{l}22.0 \% \\
(682)\end{array}$ & $\begin{array}{l}23.5 \% \\
(820)\end{array}$ & $\begin{array}{l}22.1 \% \\
(835)\end{array}$ & $\begin{array}{l}20.2 \% \\
(818)\end{array}$ & $\begin{array}{l}18.8 \% \\
(855)\end{array}$ & $\begin{array}{l}17.7 \% \\
(881)\end{array}$ & $\begin{array}{l}14.1 \% \\
(826)\end{array}$ & $\begin{array}{l}14.3 \% \\
(938)\end{array}$ & $\begin{array}{l}12.9 \% \\
(854)\end{array}$ \\
\hline Offspring & $\begin{array}{l}12.8 \% \\
(372)\end{array}$ & $\begin{array}{l}11.5 \% \\
(357)\end{array}$ & $\begin{array}{l}14.6 \% \\
(509)\end{array}$ & $\begin{array}{l}14.1 \% \\
(533)\end{array}$ & $\begin{array}{l}15.7 \% \\
(636)\end{array}$ & $\begin{array}{l}14.9 \% \\
(677)\end{array}$ & $\begin{array}{l}16.3 \% \\
(811)\end{array}$ & $\begin{array}{l}18.2 \% \\
(1066)\end{array}$ & $\begin{array}{l}18.2 \% \\
(1194)\end{array}$ & $\begin{array}{l}18.4 \% \\
(1218)\end{array}$ \\
\hline Full sibling & $\begin{array}{l}45.3 \% \\
(1316)\end{array}$ & $\begin{array}{l}41.9 \% \\
(1300)\end{array}$ & $\begin{array}{l}42.3 \% \\
(1476)\end{array}$ & $\begin{array}{l}38.7 \% \\
(1462)\end{array}$ & $\begin{array}{l}38.3 \% \\
(1552)\end{array}$ & $\begin{array}{l}35.7 \% \\
(1623)\end{array}$ & $\begin{array}{l}32.9 \% \\
(1637)\end{array}$ & $\begin{array}{l}31.7 \% \\
(1857)\end{array}$ & $\begin{array}{l}28.8 \% \\
(1889)\end{array}$ & $\begin{array}{l}27.7 \% \\
(1833)\end{array}$ \\
\hline Spouse & $\begin{array}{l}4.0 \% \\
(116)\end{array}$ & $\begin{array}{l}4.2 \% \\
(130)\end{array}$ & $\begin{array}{l}7.4 \% \\
(258)\end{array}$ & $\begin{array}{l}9.2 \% \\
(347)\end{array}$ & $\begin{array}{l}9.3 \% \\
(377)\end{array}$ & $\begin{array}{l}11.7 \% \\
(532)\end{array}$ & $\begin{array}{l}11.4 \% \\
(567)\end{array}$ & $\begin{array}{l}11.3 \% \\
(662)\end{array}$ & $\begin{array}{l}11.0 \% \\
(722)\end{array}$ & $\begin{array}{l}10.8 \% \\
(715)\end{array}$ \\
\hline $\begin{array}{l}\text { Non-spouse } \\
\text { unrelated }\end{array}$ & $\begin{array}{l}2.5 \% \\
(73)\end{array}$ & $\begin{array}{l}2.6 \% \\
(81)\end{array}$ & $\begin{array}{l}4.6 \% \\
(160)\end{array}$ & $\begin{array}{l}5.9 \% \\
(223)\end{array}$ & $\begin{array}{l}6.6 \% \\
(267)\end{array}$ & $\begin{array}{l}7.7 \% \\
(350)\end{array}$ & $\begin{array}{l}9.4 \% \\
(468)\end{array}$ & $\begin{array}{l}14.1 \% \\
(826)\end{array}$ & $\begin{array}{l}15.2 \% \\
(997)\end{array}$ & $\begin{array}{l}17.6 \% \\
(1165)\end{array}$ \\
\hline
\end{tabular}

Source: 2003 OPTN/SRTR Annual Report, Table 2.8.

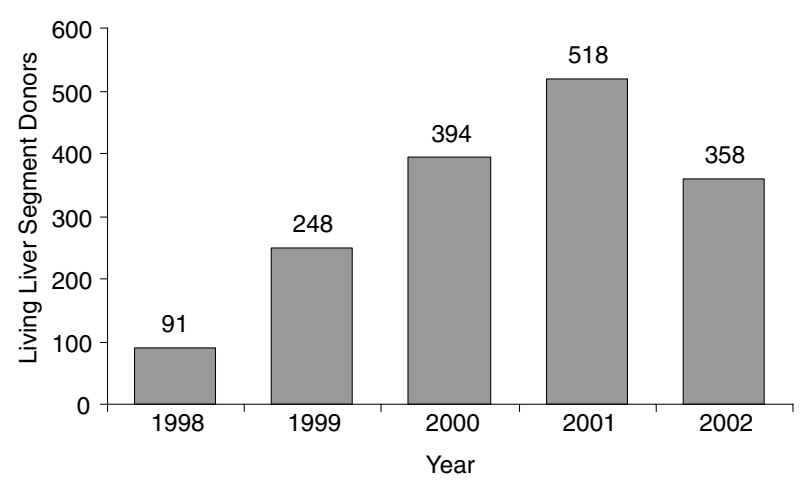

Source: 2003 OPTN/SRTR Annual Report, Tables 2.10.

Figure 8: Living liver segment donors, 1998-2002.

Overall, depending on the organ type, opportunities to increase the extraction of available organs seem to exist, and may be of varying magnitude depending upon the organ type. Most obvious is the ability to use damaged livers successfully because of the regenerative capacity of that organ, leading to a high utilization rate. Approaches to effect this change will require more aggressive analysis and policies that create incentives for greater use of these organs. Today, transplant centers are compared primarily on their post-transplant survival rates, which do not create incentives to serve the population at need by expanding donor selection criteria aggressively. On a limited basis, SRTR and Human and Health Services have analyzed the probability of survival on the waiting list and other factors, and they have attempted to document rates of refusal of donor offers for different transplant centers. Current data collection and reporting does not adequately demonstrate the gap in utilization between best and worst practices, and such data will be necessary in promoting change.

\section{References}

1. Dickinson DM, Bryant PC, Williams MC et al. Transplant data: sources, collection, and caveats. Am J Transplant 2004; 4(Suppl 9): $13-26$
2. Wolfe RA, Schaubel DE, Webb RL et al. Analytical approaches for transplant research. Am J Transplant 2004; 4(Suppl 9): 106-113.

3. United Network for Organ Sharing (Richmond, VA) Work Group 4. UNOS Consensus Conference on the Consent Process: Research to Practice. 2003.

4. Nathan HM, Conrad SL, Held PJ et al. Organ donation in the United States. Am J Transplant 2003; 3 (Suppl. 4): 29-40.

5. Sheehy E, Conrad SL, Brigham LE et al. Estimating the number of potential organ donors in the United States. NEJM 2003; 349: 667-674.

6. Siminoff LA, Lawrence RH, Arnold RM. Comparison of black and white families' experiences and perceptions regarding organ donation requests. Critical Care Med 2003; 31: 146-151.

7. Siminoff L. Family consent: developing a model intervention to increase consent to organ donation. National Consent Conference on Organ Donation, Orlando, Florida, April 2003.

8. McCunn M, Maurutz W, Dutton RP, Handley C, Scalea TM. Impact of culture and policy on organ donation: a comparison between two urban trauma centers in developed nations. J Trauma 2003; 54: 995-999.

9. Gimbel RW, Strosberg MA, Lehrman SE, Gefanas E, Taft F. Presumed consent and other predictors of cadaveric organ donation in Europe. Prog Transplant 2003; 1: 17-23.

10. Roberts CJ. Presumed consent for organ procurement - does it have a future in the U.S.? J Neurosci Nurs 2003; 35: 107-113.

11. Webb $M$, Dindo $D$, Demartines $N$ et al. Kidney transplantation from donors without a heartbeat. NEJM 2002; 347 (4): 248255.

12. Rudich SM, Kaplan B, Magee JC et al. Renal transplantations performed using non-heart-beating organ donors: going back to the future? Transplantation 2002; 74: 1715-1720.

13. Daemen JHC, de Wit RJ, Bronkhorst MWGA et al. Non-heartbeating program contributes $40 \%$ of kidneys for transplantation. Transplant Proc 1996; 28: 105.

14. Metzger RA, Delmonico FL, Feng S et al. Expanded criteria donors for kidney transplantation. AM T Transplant 2003; 3 (Suppl. 4): 114-125.

15. Port FK, Bragg JL, Metzger RA et al. Donor characteristics associated with reduced graft survival: an approach to expanding the pool of kidney donors. Transplantation 2002; 74: 12811286.

16. Rosengard BR, Feng S, Alfrey EJ, Zaroff $\mathrm{J}$ et al. Report of the Crystal City Meeting to maximize the use of organs recovered from the cadaver donor. Am J Transplant 2002; 2 (8): 701-711.

17. New York Organ Donor Network data, 2002. http://www.nyodn.org

18. Ochs R. Widow fights for oversight of surgeries. Newsday, August 18, 2002, A35 


\section{Organ donation and utilization}

19. Shiffman ML, Richardson MC, Everhart JE, Hoofnagle JH et al. A survey of liver transplantation from living adult donors in the United States. NEJM 2003; 348: 818-825.

20. Grady D. Hospital is fined for 'woeful care': Mt. Sinai cited for deficiencies after liver donor's death. New York Times 13 March 2002.

21. Josefson D. Transplants from live patients scrutinised after donor's death. BMJ 2002; 324: 754. 